\title{
Intervención psicosocial aplicado a la Comunidad de la Tercera Edad- Asoviche Palmira (Modelo de Bienestar Lin Y Ensel)
}

\author{
Martha Lucía Fuertes D. ${ }^{1}$ \\ Julio Cesar Montoya R. ${ }^{2}$ \\ María Isabel Posso Ch. ${ }^{3}$
}

\section{RESUMEN}

La intervención comunitaria es un tipo de intervención social enfocada a la comunidad. Parte de la realidad de que cada comunidad tiene su propia fuerza reguladora, que ayuda al individuo a desarrollarse de forma integral en el contexto en el que está inmerso. En este mismo orden y dirección, el presente ejercicio investigativo, propone este tipo de intervención en un grupo social conformado por mujeres y hombres de la tercera edad, agremiación denominada por sus fundadoras, Asoviche (Asociación de Viejas Chéveres), del municipio de Palmira.

En este propósito, la investigación tuvo como etapa inicial, el desarrollo de un diagnóstico situacional de esta comunidad de adultos mayores para identificar posibilidades de intervención.

\footnotetext{
${ }^{1}$ Contadora Pública, Especialista en Finanzas, Maestría en Administración, docente Universidad Nacional Abierta y a Distancia - UNAD. martha.fuertes@unad.edu.co

2 Administrador de Empresas, Especialista en Pedagogía para el Desarrollo del Aprendizaje Autónomo, Maestría en Administración de Empresas. Docente de la Universidad Nacional Abierta y a Distancia UNAD. julio.montoya@unad.edu.co

${ }^{3}$ Psicóloga, Especialista en pedagogía del desarrollo del aprendizaje Autónomo, Magister en Administración de organizaciones. Docente. Universidad nacional Abierta y a Distancia- UNAD. maria.posso@unad.edu.co
} 
Una vez obtenido el propósito inicial se procedió a plantear el proceso de intervención incluyendo criterios de logro, alcances, objetivos del proceso, de acuerdo a las categorías identificadas en el diagnóstico, y el Plan de Acción asociado.

Atendiendo a la concreción de las etapas intervencionistas, la parte final correspondió a la medición del impacto generado en esta comunidad en particular por la intervención psicosocial, y los logros obtenidos.

Palabras clave: intervención, comunidad, adulto mayor, apoyo social, bienestar

\section{Introducción}

La intervención comunitaria es un tipo de intervención social enfocada a la comunidad. Parte de la realidad de que cada comunidad tiene su propia fuerza reguladora, que ayuda al individuo a desarrollarse de forma integral en el contexto en el que está inmerso. El ser humano es un ser eminentemente social, y en consecuencia se potencia cuando interactúa con otros, de ahí que las personas puedan "literalmente" alcanzar momentos brillantes de participación individual en contextos comunitarios, incluso por encima de las gestas que puedan tener por acciones individuales.

Una de las comunidades donde se puede confirmar esta premisa, son los grupos de la tercera edad; hoy en día, en los barrios de estratos socioeconómicos medios y medios bajos, es muy común encontrar en los parques, canchas o zonas verdes, adultos mayores, ataviados con ropas deportivas en actitud de esparcimiento y recreación.

Gran parte de la sociedad, se identifica con estas comunidades, considerándolas como un ejemplo y confirmación de que "la juventud se lleva en el espíritu y no en el cuerpo"; en el campo disciplinar de la psicología, la intervención psicosocial aprueba estas agremiaciones apoyando profesionalmente estas agrupaciones, ofreciéndoles a través de modelos y teorías un conjunto de estrategias proclives a promover en ellos, la autoestima, la autoconfianza y su inclusión social.

\section{Antecedentes teóricos}

Los Psicólogos N. Lin y W. Ensel., fueron continuadores de los postulados del estrés psicosocial. Para estos autores, el estrés puede señalarse en tres entornos: (1) Social, (2) Psicológico, (3) Fisiológico. Para sustentar sus planteamientos propusieron 
dos teorías complementarias: la teoría del Afrontamiento y la Teoría de la inhibición del Estrés.

En el centro de este modelo podemos encontrar el apoyo social como recurso fundamental del bienestar psicosocial de las personas. La estructura está en relación directa con las fuentes de apoyo social las cuales tienen una correlación entre el individuo y su realidad cotidiana. Estas denotaciones establecen variables objetiva del apoyo.

Lin y Ensel señalan tres (3) estratos: uno externo y más amplio en el cual la persona establece apoyo social, se identifica y participa con otras personas de la sociedad. En ella el individuo hace parte de organizaciones informales (asociaciones, grupos cívicos, grupos de autoayuda, etc.), actuando de forma voluntaria. (Lin \& Ensel, 1989)

Un segundo estrato, más próximo al individuo, son las redes sociales (familiares, amigos, vecinos del barrio, compañeros de trabajo o estudio) en las cuales se establecen vínculos afectivos importantes y se denotan lazos profundos hacia los otros. El último nivel es aquel en el cual la persona establece el más íntimo contacto con aquellos que son significativas para sí mismo, en donde los sentimientos de compromiso se profundizan y se determinan un amplio sentido de responsabilidad y deseo de bienestar del otro. (pareja, hijos, padres, hermanos, amigos íntimos y en algunos casos compañeros de trabajo.

Las relaciones sociales implican una percepción por parte del otro, acerca del apoyo que ha recibido (dimensión subjetiva). Y este sentir la "ayuda" del otro hace que la persona que recibe el apoyo tenga una visión positiva de la asistencia. No es la cantidad de relaciones de apoyo que se tengan sino la calidad y la percepción positiva que se tenga de ellas. En este sentido, Turner, (1990) y más recientemente Hawkley \& Cacciopo, (2006) concluyen que "el elemento fundamental no es la mera inserción objetiva en una red social densa, sino la existencia de una red de relaciones con un significado de apoyo emocional, informacional y material percibido por el sujeto." (Buelga \& Cols, 2009).

Dentro de los procesos de las relaciones con los demás y el establecimiento de diferentes redes, el apoyo social presenta dos funciones esenciales: (1) Instrumentales, (2) expresivas. Las primeras se caracterizan, en el marco de las relaciones sociales, por ser un medio para alcanzar metas a través de una ayuda material o un servicio: consecución de un empleo, préstamo de dinero, cuidado de un familiar. En las funciones expresivas las relaciones sociales son un fin y un medio por medio de los cuales el ser humano comparte sus sentimientos, manifiesta sus experiencias, expone los pensamientos propios, expresa los sentimientos de sentirse cuidado, valorado, querido, etc.

\section{Apoyo social en la vejez}

Lin \& Ensel, (1989) en uno de los intentos más rigurosos, lo definen como el conjunto de provisiones dadas o recibidas proporcionadas por la comunidad, las redes 
sociales y las personas de confianza, que se pueden producir tanto en situaciones cotidianas como de crisis.

\section{Elementos objetivos y subjetivos en la calidad de vida}

Ilustración 1. Dimensiones y calidad de vida

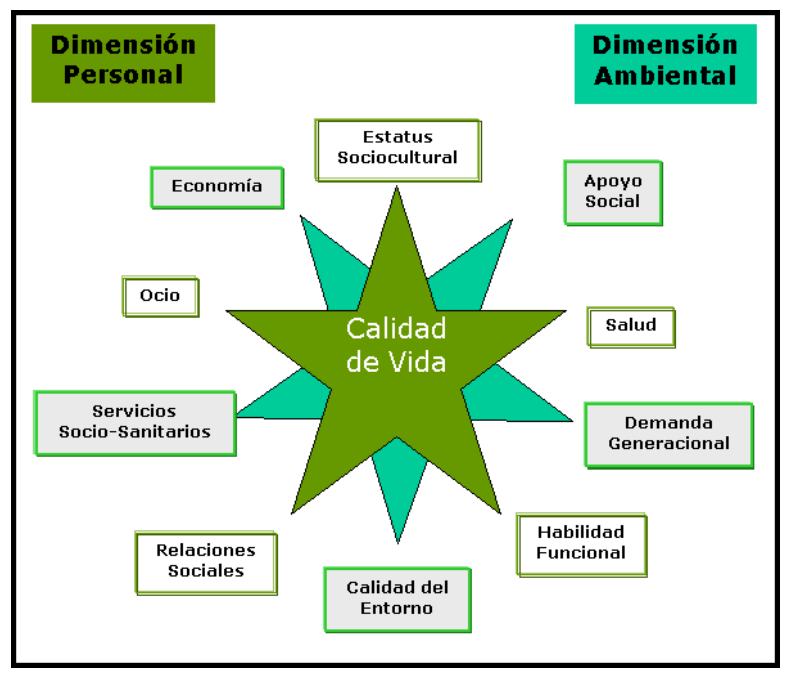

Fuente: Hidalgo Valera, 2010

Las dimensiones objetivo-subjetiva como en la personal-socioambiental se sugiere el apoyo social como factor condicionante. En la primera dimensión, aparece como extremo del eje que contiene la satisfacción social como medida objetiva;

mientras que en la segunda, se ve enfrentado a las relaciones sociales. Desde ambas perspectivas se destaca la importancia de los vínculos sociales y la satisfacción que la persona experimenta con ellos.

Paradigma del estrés vital (Lin y Ensel, 1989) 


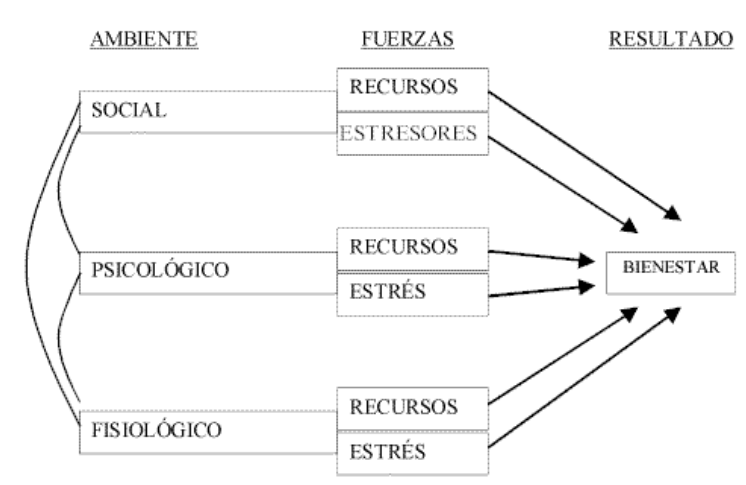

Lin \& Ensel, (1989) proponen un paradigma integrador (figura anterior), en el que incorporan tanto el ambiente social como el puramente fisiológico, así como, por supuesto, el psicológico. Cada uno de estos ámbitos, según los autores, viene determinado por la presencia de estresores y de recursos que facilitan su afrontamiento.

En este sentido, un claro estresor fisiológico para el sujeto será la presencia de una enfermedad, mientras que la práctica de ejercicio físico, una dieta adecuada o, en general, el mantenimiento de unos hábitos saludables constituyen recursos útiles para hacer frente a estas adversidades. El padecimiento de síntomas depresivos supone un claro estresor psicológico, mientras que una alta autoestima se sitúa dentro de los recursos psicológicos. Por último, el apoyo social representa el recurso social más importante con el que superar las adversidades que acompañan a los acontecimientos vitales estresantes. Todos elementos en conjunto van a ejercer su influencia sobre el bienestar del sujeto.

\section{Diagnóstico Situacional (Objetivo 1)}

Para desarrollar esta parte, se hizo uso de la metodología "cartografía social", una técnica de trabajo que permite que tanto personas de la comunidad como académicos, profesionales, funcionarios públicos, y otros actores sociales, se sienten alrededor de una mesa, compartan, discutan y concerten puntos de vista, información y conocimientos sobre la realidad de un territorio determinado. En el caso puntual de la comunidad sujeto de estudio (Asoviche), se planteó por parte de la psicóloga (interventora psicosocial) un ejercicio taller, donde sus miembros concertaran en tres lienzos (su realidad pasada, su realidad presente y su realidad futura). Para ello se le facilitaron marcadores y unas revistas viejas para que ellas (ellos) recortaran y pegaran en cada lienzo una imagen que mejor reflejara lo que quisiesen representar.

La idea era que entre todas, ellas se pusieran de acuerdo a ilustrar situaciones, eventos o circunstancias vividas, durante su participación activa en el grupo, antes (Lienzo 1); durante (Lienzo 2), y después (Lienzo 3).

Los lienzos (tres hojas de papelógrafo, una por cada etapa de tiempo; antes, durante y después) se les entregaron completamente en blanco, y se les sugirió que colocaran el titulo correspondiente, y que describieran con ilustraciones propias o 
extraídas de las revistas, las situaciones o vivencias que tuvieran, tienen o tendrían de acuerdo a su percepción individual pero un contexto colectivo.

\section{Cartografía Social}

\section{Fase I Antes (Como se veían antes)}

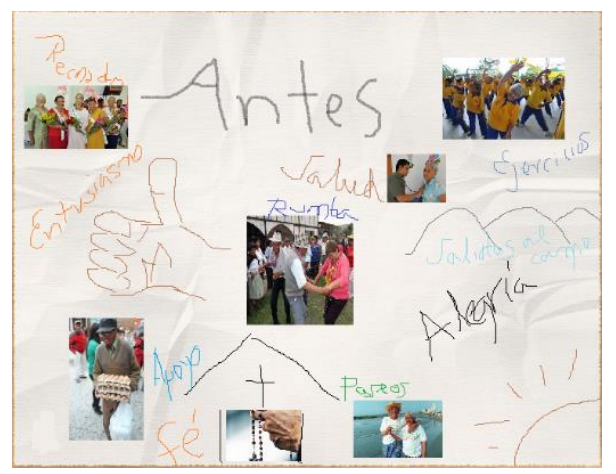

- Reinado: Para este grupo este certamen que se realizaba cada año resultaba muy significativo, pues tipificaba la negación del sentirse viejo, la perpetuida de la belleza exterior e interior

- Entusiasmo: La señal de la mano con "el pulgar arriba" simboliza para este grupo, el ánimo que se tenía en aquel tiempo, la disposición siempre positiva para cada una de las actividades que se emprendían.

- Apoyo: La imagen escogida da cuenta de que para este grupo, mucha gente les colaboraba no solo con la logística de los eventos, sino con comida, trajes, divisas deportivas, elementos lúdicos, etc.

- Rumba: Para esta agremación, la rumba es la actividad estrella, pues como dice una de sus fundadoras, (Sra Rosalba Hernández, 84 años) el espíritu alegre de la parranda no debe de perderse jamás.

- Fé; Para Margarita Bejarano de Valencia (66 años), es muy importante la cuestión religiosa, ella lidera la parte religiosa, y manifiesta que la Virgen de la Caridad del Cobre ha sido la patrona de este grupo.

- Paseos y salidas al campo: esta parte la lideraba en aquel entonces, la Sri Gloria Arosemena de Meyendorff, una de sus fundadoras ya fallecida, quien tenía una finquita hacia la montaña e invitaba a todos los demás miembros a quedarse en ella, o estar en el dia para celebrar cualquier evento lúdico, de igual forma, ella se encargaba de la consecución del transporte, el refrigerio y la logística de las salidas.

- Salud: En lo concerniente a este apartado, la Sra Carmen de Bejarano, como miembro activo de las damas grises de la Cruz Roja, habia conseguido la cobertura gratuita de la atención básica médica para este grupo. De igual forma, cuando la Alcaldia de Palmira, realizaba brigadas de salud para la tercera edad, al grupo Asoviche siempre se le tenia en cuenta.

- Ejercicios: Había en los primeros años, dos sitios para practicar actividades físicas, el Parque Infantil de El Recreo, quien prestaba en forma libre sus instalaciones, y el Coliseo de Ferias, quienes permitían el acceso a los miembros de este grupo para hacer sus prácticas en los pabellones posteriores. 
- Alegría: Una de las características más sobresalientes de Asoviche, recuerda la Sra Calina de Rivera, era la actitud siempre alegre de sus miembros, la recocha, el apunte, el chistecito..era el lenguaje que se modulaba en los inicios de la Asociación.

Fase II -Durante (Cómo se ven ahora)

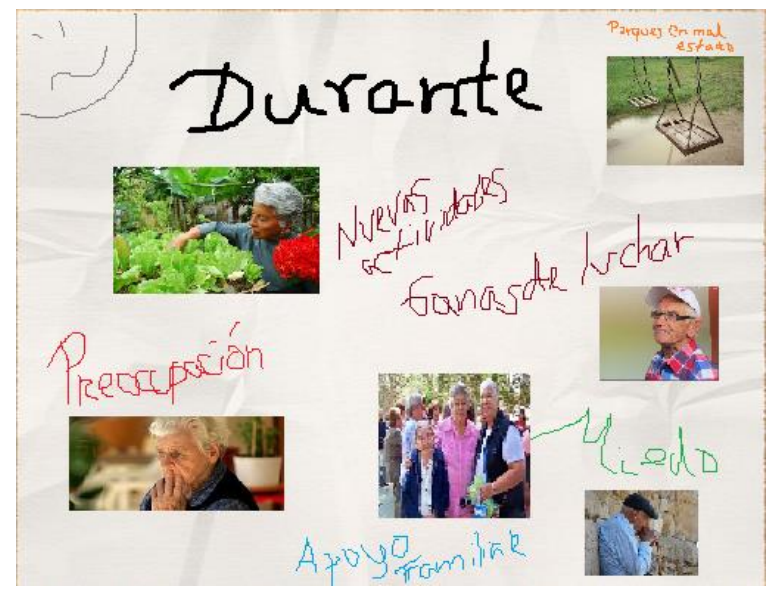

Preocupación: Nidia Gonzales vda de Penagos, dice que el grupo en términos generales, ha entrado en una etapa de monotonía y desesperanza, que se reflejan en una constante preocupación por el futuro de la asociación. A partir de la muerte de dos de sus fundadoras (la Sra. Arosemena, y la Sra Merceditas Rojas), las cosas cambiaron, pues ellas eran las que constantemente animaban a los demás. El sentimiento de preocupación, reposa también en el sostén financiero de la asociación, puesto que no se ha podido lograr una estabilidad económica que permita sostenerse sin requerir a solicitar ayuda a terceros.

Nuevas actividades: Han menguado hoy dia, las actividades como paseos y viejotecas, en la actualidad, los eventos son más de recogimiento, como grupos de oración, visita a enfermos, asistencia a conferencias sobre la calidad de vida, o de prevención en salud, entre otras.

Ganas de luchar: Don Hernán de la Cadena, uno de los adalides de la Asociación, dice que a pesar de las dificultades propias del día a día de la Asociación, sus miembros muestran siempre un espíritu combativo, los unos animan a los otros, y así es como se sostiene.

Parques en mal estado: Todos los miembros convinieron que en lo que hace referencia a los parques del barrio y los aledaños al mismo, se encuentran en mal estado, lo que ha dificultado las actividades lúdico-recreativas, el problema recurrente es que las zonas verdes que quedan están atestadas de "viciosos" o llenas de personas con sus mascotas, que no siempre tienen la cultura de recoger los excrementos de sus animales.

Miedo: Este sentimiento es inocultable en algunos de sus miembros, la Sra Graciela de Naranjo, dice que algunos miembros han fallecido, otros se han cambiado de barrio, y otros pues se han desanimado, lo que se ha deteriorado la estructura del grupo, el 
"miedo" expresado, es debido a que muchas de estas personas viven solas, y ven en el grupo un paliativo para enfrentar el abandono sistemático de sus hijos, y si el grupo se llegara a desintegrar, la situación sería muy triste y compleja para enfrentar la soledad y el olvido.

Apoyo familiar: Otra parte del grupo por el contrario, afirma que sus familiares si los apoyan decididamente, y que siempre están dispuestos a hacerlo, pareciera una contradicción que unos opinen una cosa y otros otra, pero son circunstancias que conviven cuando los grupos son de diferentes grupos etarios.

\section{Fase III: Después (Como se ven en el futuro)}

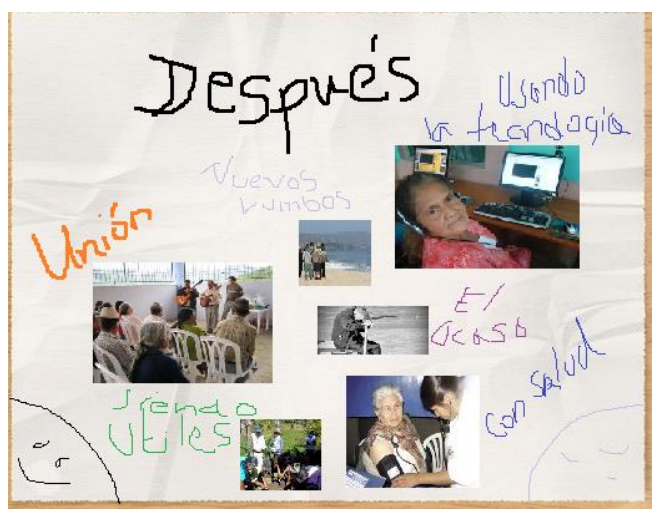

Unión: Este valor tiene mucho peso entre los miembros de Asoviche, ellos sostienen que a futuro se ven unidos, asi algunos falten porque hayan fallecido, o se hayan ido, ellos piensan que solo fortalecidos en unión podrán sobrevivir a su causa comunitaria.

Nuevos Rumbos: La gran mayoría considera que ellos tienen vida para rato, y se ven viajando y conquistando nuevos rumbos como al principio, la Sra, Nubia Sandoval de Burbano, dice que hace unos años, cada mes se viajaba como mínimo dos veces al año a otros departamentos, ella tiene recuerdos imborrables de ese viaje que se hizo al Eje Cafetero. 
Siendo útiles: Uno de los temores más arraigados en la tercera edad, es la imposibilidad fisiológica y mental de seguir siendo útiles, pero los miembros de Asoviches, tienen pensado solicitar apoyo para formar una microempresa de alimentos prefabricados (empanadas, dedos de queso, etc.)

Usando nueva tecnología: El grupo en pleno, se muestra deseoso, que en los años venideros, todos y cada uno de los miembros, pueda usar la tecnología sin ningún problema, de hecho hay algunos que utilizan los teléfonos inteligentes y tablets de una manera óptima; otros por el contrario dicen que aún les da cierto temor utilizar estos aparatos.

El ocaso: Para Luz Dary Monsalve, una de las líderes más activas de la Asociación, hay que pensar también en situaciones realistas como el "ocaso"; es innegable como ella lo manifiesta que así uno "le meta ganas a la vida", la vida misma va cobrando factura, en salud, en soledad, en situación financiera, en olvido, hay que pensar en todo, aun hasta en la muerte.

Con salud: Las miembros más longevas, en forma paradójica, se ven a futuro con salud, como es el caso Doña Rosalba Hernández (84 años), y la Sra Ermidia Carrejo (82 años), respectivamente, ambas sostienen que mientras Dios les de ánimos, y salud, ellas estarán contentas y dispuestas a servir a la comunidad con alegría y entusiasmo. 


\section{Plan de acción de la intervención psicosocial}

La parte final del proceso interventor corresponde a la estructuración del Plan de Acción como resultado del diagnóstico realizado en los talleres mediados por la cartografía social, los diálogos con los miembros de esta comunidad y la observación participante

\begin{tabular}{|c|c|c|c|c|c|}
\hline Tópico asociado & $\begin{array}{c}\text { Actividad } \\
\text { propuesta }\end{array}$ & Objetivo & Metodología & Recursos & $\begin{array}{c}\text { Resultados } \\
\text { esperados }\end{array}$ \\
\hline $\begin{array}{l}\text { Presentación de la } \\
\text { propuesta. }\end{array}$ & $\begin{array}{l}\text { Socialización de } \\
\text { la propuesta }\end{array}$ & $\begin{array}{l}\text { Dar a conocer la } \\
\text { propuesta al grupo de } \\
\text { la tercera edad }\end{array}$ & $\begin{array}{l}\text { Exposición por } \\
\text { parte del } \\
\text { estudiante } \\
\text { investigador, } \\
\text { mediante } \\
\text { presentación de } \\
\text { diapositivas. }\end{array}$ & $\begin{array}{l}\text { Carteles, } \\
\text { marcadores, } \\
\text { video Ben. }\end{array}$ & $\begin{array}{l}\text { Que todos los } \\
\text { integrantes } \\
\text { del grupo de } \\
\text { la tercera } \\
\text { edad } \\
\text { conozcan y } \\
\text { aprueben la } \\
\text { aplicación de } \\
\text { la propuesta. }\end{array}$ \\
\hline $\begin{array}{l}\text { Grupo las } \\
\text { Danzaoras }\end{array}$ & $\begin{array}{l}\text { Organización del } \\
\text { grupo de danzas } \\
\text { de la tercera edad } \\
\text { Las Danzaoras }\end{array}$ & $\begin{array}{l}\text { Convocar a los } \\
\text { señores de la tercera } \\
\text { edad para la } \\
\text { organización del } \\
\text { grupo de las } \\
\text { Danzaoras como un } \\
\text { estímulo para la sana } \\
\text { recreación y } \\
\text { estrategia para } \\
\text { rescatar } \\
\text { manifestaciones } \\
\text { culturales de la } \\
\text { comunidad. }\end{array}$ & $\begin{array}{l}\text { Convocatoria } \\
\text { por parte del } \\
\text { estudiante } \\
\text { investigador } \\
\text { para la } \\
\text { conformación } \\
\text { del grupo, } \\
\text { concertación } \\
\text { para la elección } \\
\text { del líder o } \\
\text { director del } \\
\text { grupo }\end{array}$ & $\begin{array}{l}\text { Grabadora, } \\
\text { CD, memoria } \\
\text { USB. }\end{array}$ & $\begin{array}{l}\text { Que los } \\
\text { integrantes } \\
\text { del grupo se } \\
\text { animen a } \\
\text { participar } \\
\text { espontáneam } \\
\text { ente en la } \\
\text { conformación } \\
\text { del grupo de } \\
\text { baile. } \\
\text { Que el adulto } \\
\text { mayor se } \\
\text { sienta } \\
\text { orgulloso de } \\
\text { ser } \\
\text { representante } \\
\text { de una } \\
\text { tradición } \\
\text { cultural de su } \\
\text { comunidad y } \\
\text { sirva de } \\
\text { ejemplo a las } \\
\text { nuevas } \\
\text { generaciones } \\
\text { en la } \\
\text { valoración de } \\
\text { sus raíces } \\
\text { culturales. }\end{array}$ \\
\hline Hábitos saludables. & $\begin{array}{l}\text { Club de } \\
\text { caminantes }\end{array}$ & $\begin{array}{l}\text { Organizar caminatas } \\
\text { con los adultos } \\
\text { mayores }\end{array}$ & $\begin{array}{l}\text { Recorrido por } \\
\text { las calles de la } \\
\text { población en } \\
\text { las horas de la } \\
\text { mañana. }\end{array}$ & $\begin{array}{l}\text { Indumentaria } \\
\text { adecuada, } \\
\text { agua, refrigerio }\end{array}$ & $\begin{array}{l}\text { Que adulto } \\
\text { mayor } \\
\text { adquiera el } \\
\text { hábito de } \\
\text { realizar }\end{array}$ \\
\hline
\end{tabular}




\begin{tabular}{|c|c|c|c|c|c|}
\hline & & & & & $\begin{array}{l}\text { caminatas } \\
\text { para } \\
\text { favorecer su } \\
\text { estado de } \\
\text { salud }\end{array}$ \\
\hline Recreación & $\begin{array}{l}\text { Jornadas } \\
\text { deportivas y } \\
\text { recreativas }\end{array}$ & $\begin{array}{l}\text { Campeonato de } \\
\text { dominó por parejas, } \\
\text { parqués y cartas, } \\
\text { hula-hula }\end{array}$ & $\begin{array}{l}\text { Organizar en } \\
\text { forma } \\
\text { aleatoria los } \\
\text { grupos que } \\
\text { disputaran las } \\
\text { partidas } \\
\text { de juegos y } \\
\text { seleccionar un } \\
\text { ganador por } \\
\text { cada grupo } \\
\text { para la } \\
\text { siguiente ronda. }\end{array}$ & $\begin{array}{l}\text { Juegos de } \\
\text { dominó, cartas, }\end{array}$ & $\begin{array}{l}\text { Brindar } \\
\text { momentos de } \\
\text { esparcimiento } \\
\text { s al adulto } \\
\text { mayor. }\end{array}$ \\
\hline Lúdica & Concurso de baile & $\begin{array}{l}\text { Certamen de bailes } \\
\text { por parejas con } \\
\text { ritmos nacionales e } \\
\text { internacionales } \\
\text { (cumbia, merengue, } \\
\text { pasodoble, danzón, } \\
\text { rock, reggaetón, } \\
\text { bachata, entre otros) }\end{array}$ & $\begin{array}{l}\text { Organizar en } \\
\text { forma aleatoria } \\
\text { las parejas que } \\
\text { disputaran las } \\
\text { diferentes } \\
\text { rondas, las } \\
\text { parejas que no } \\
\text { ejecuten los } \\
\text { pasos } \\
\text { requeridos, las } \\
\text { van } \\
\text { descalificando }\end{array}$ & $\begin{array}{l}\text { Ritmos } \\
\text { musicales, } \\
\text { adornos } \\
\text { alegóricos }\end{array}$ & $\begin{array}{l}\text { Brindar } \\
\text { momentos de } \\
\text { esparcimiento } \\
\text {, gozo y } \\
\text { alegría al } \\
\text { adulto mayor. }\end{array}$ \\
\hline Manualidades & $\begin{array}{l}\text { Taller de } \\
\text { artesanías }\end{array}$ & $\begin{array}{l}\text { Aprovechar las } \\
\text { destrezas manuales } \\
\text { de los adultos } \\
\text { mayores para } \\
\text { elaborar productos } \\
\text { artesanales que } \\
\text { generen además de } \\
\text { entretención ingresos } \\
\text { económicos. }\end{array}$ & $\begin{array}{l}\text { Talleres } \\
\text { prácticos. Estos } \\
\text { se realizaran en } \\
\text { jornadas de tres } \\
\text { horas durante } \\
\text { dos días de la } \\
\text { semana (en las } \\
\text { horas de la } \\
\text { tarde). }\end{array}$ & $\begin{array}{l}\text { Madera, } \\
\text { mimbre, tijeras, } \\
\text { puntillas, } \\
\text { martillo, lijas. }\end{array}$ & $\begin{array}{l}\text { Que el adulto } \\
\text { mayor se } \\
\text { sienta útil en } \\
\text { su entorno } \\
\text { familiar y } \\
\text { social }\end{array}$ \\
\hline
\end{tabular}

\section{Resultados y discusión}

Hubo dos momentos de intervención psicosocial con base en el Modelo de Lin y Ensel, ambos direccionados al mejoramiento de la calidad de vida, el primero relacionado con los procesos de intervención como tal con base en los hallazgos de la cartografia social y su relación con el paradigma del estrés vital; y el segundo asociado con la propuesta o plan de acción que se desarrolló presencialmente con esta comunidad. 
Queda claro que esta comunidad tiene una vocación de servicio inquebrantable y unas ganas de vivir increíbles, por lo que fue de gran recibo para ellas planteas mejoras y ayudas psicosociales a sus sueños de vida.

\section{Conclusiones}

- El diagnóstico situacional dio cuenta de una asociación entusiasta, con ganas de luchar, unida, pero disminuida por las circunstancias propias de sus contextos social, fisiológico y psicológico

- $\quad$ En el diagnóstico de la cartografía social aparecieron ilustraciones con elementos y encontrados, incluso contradictorios, lo que demuestra que la intervención psicosocial requería tomar acciones de conformidad a la unificación de criterios.

- En los talleres y diálogos informales, y mediante la observación no participante, se pudo apreciar una sinergia grande entre las integrantes, lo que facilitó los procesos y mediaciones intervencionales.

- El apoyo de grupos de interés a esta comunidad en particulares resulta insuficiente, no existe una colaboración continua, aparte de ello, la programación de actividades se dificulta por falta de espacios físicos.

\section{Trabajos citados}

Buelga, S., \& Cols, Y. (2009). Psicología Social Comunitaria. México: Trillas.

Hawkley, W., \& Cacciopo, J. (2006). Social neuroscience. Book review of the Neuroscience of social interactions . American Journal of Psychology,.

Lin, N., \& Ensel, W. (1989). Life stress and health: Stressors and resources.

Turner, J. (1990). Redescubrir el grupo social. Madrid: Morata. 